\title{
Brominated flame retardants, a cornelian dilemma
}

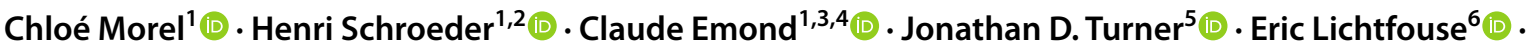 \\ Nathalie Grova ${ }^{1,2,5}$
}

Published online: 23 January 2022

(c) The Author(s), under exclusive licence to Springer Nature Switzerland AG 2022

\section{Introduction}

Dying immediately in flames or from poisoning in the long run is the cornelian dilemma induced by the use of brominated flame-retardants. Indeed, these compounds have been intensively used to slow down fires in houses and buildings, thus increasing escape time from about $2 \mathrm{~min}$ to $20 \mathrm{~min}$. They were initially thought to be safe, notably because their adhesive properties make them unlikely to reach human tissues. However, recent research has disclosed that brominated flame-retardants are developmental neurotoxicants that trigger neurodevelopmental deficits in young children (Gray and Billock 2017) (Fig. 1). Since infants and young children have been exposed to brominated flame-retardants since the early 1970s, we are now observing the long-term developmental impact of this 50-year-old ticking time bomb. Here we discuss the occurrence of brominated flame-retardants, exposure at home, neurodevelopmental diseases and alternative flame retardants.

Nathalie Grova

nathalie.grova@lih.lu

Chloé Morel

Chloe.morel@univ-lorraine.fr

Henri Schroeder

henri.schroeder@univ-lorraine.fr

Claude Emond

claude.emond@pksh.ca

Jonathan D. Turner

jonathan.turner@lih.lu

Eric Lichtfouse

eric.lichtfouse@gmail.com

1 Calbinotox, Faculty of Science and Technology,

University of Lorraine, Campus Aiguillettes, B.P. 70239,

54506 Vandoeuvre-lès-Nancy, France

\section{Industrial products}

Brominated flame-retardants are industrial chemicals used to reduce the risk of fatal fire injuries (Ryan and Rawn 2014). They are extensively incorporated into consumer products such as domestic insulation, carpets, electronic devices, clothes, toys, and plastic products. They inhibit fire ignition or slow down the speed of fire combustion, and, consequently, they reduce the risk of fire-injury and property damage. Brominated flame-retardants belong to a wide family of more than 175 different flame retardants (Birnbaum and Staskal 2004). They occur in building materials worldwide and are still incorporated in many new materials (Frederiksen et al. 2009; Malliari and Kalantzi 2017).

Brominated flame-retardants are particularly abundant indoors. For instance, electronics and furniture contain polybrominated diphenyl ethers, circuit boards contain tetrabromobisphenol $\mathrm{A}$, and polystyrene building materials contain hexabromocyclododecane. These three compounds are predominant both in indoor dust and in human tissues (Frederiksen et al. 2009). Hexabromocyclododecane has not been imported in the USA since 2018 (USEPA 2020). In Europe, hexabromocyclododecane and polybrominated

2 UMR Inserm 1256 nGERE, Nutrition-Génétique et Exposition aux risques environnementaux, Institute of Medical Research (Pôle BMS, University of Lorraine, B.P. 184, 54511 Vandoeuvre-lès-Nancy, France

3 PKSH Inc, Mascouche, QC, Canada

4 School of Public Health, DSEST, University of Montreal, Montreal, QC, Canada

5 Immune Endocrine Epigenetics Research Group, Department of Infection and Immunity, Luxembourg Institute of Health, 29, rue Henri Koch, L-4354 Esch-Sur-Alzette, Grand Duchy of Luxembourg

6 Aix-Marseille Univ, CNRS, IRD, INRAE, CEREGE, 13100 Aix en Provence, France 
Fig. 1 Brominated flame-retardants are synthetic chemicals incorporated in a wide variety of products such as plastics, textile and electric equipment, to make them less flammable. Once thought to be safe, there is now growing concern on their toxic effects because they occur widely in natural media

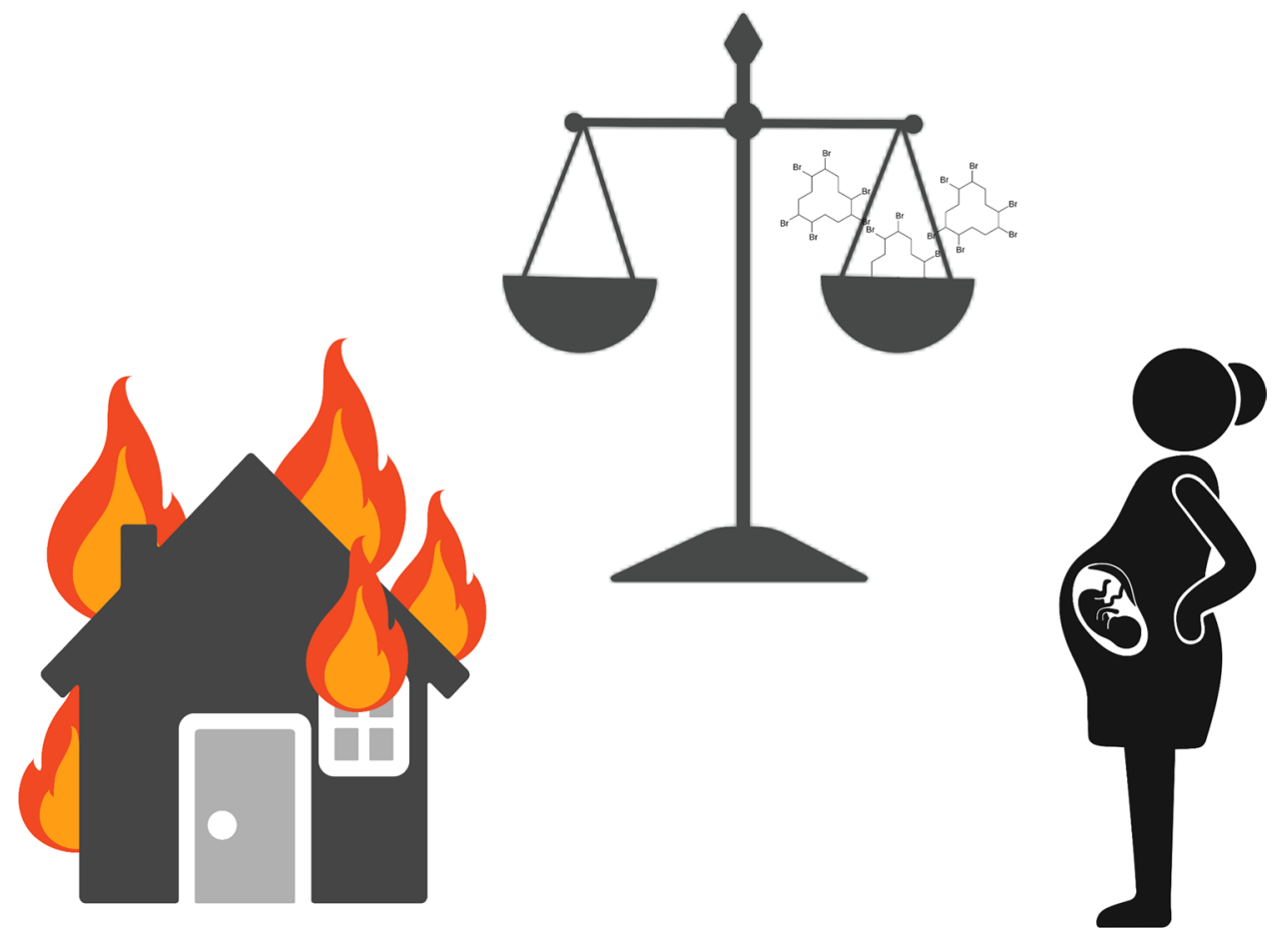

diphenyl ethers are strictly controlled by legislation and import restriction, both in marketable goods and in waste (Sharkey et al. 2020a). Tetrabromobisphenol A is still used in manufactured products in Europe and only regulated at concentration above $0.1 \%$. Implementating a new regulation in Europe could be an effective method to reduce the release of tetrabromobisphenol A in the environment (Lucattini et al. 2018; Malkoske et al. 2016).

Electronics and textile are major contributors of brominated flame-retardants in the environment. Here, the three largest producers of e-waste worldwide are the European Union with 10.07 million tons (Mt), China with $7.21 \mathrm{Mt}$ and the USA with $6.3 \mathrm{Mt}$, which are also global leaders as manufacturers and exporters of textile (Sharkey et al. 2020b). In the Middle East, Australia, and Africa, levels of brominated flame-retardants are usually low in indoor spaces (Malliari and Kalantzi 2017).

\section{Exposure at home}

Indoor air quality is a major source of concern in health risk assessment (Azuma et al. 2020). Indeed, indoor air is much more polluted than the outdoor atmosphere. As a consequence, opening windows regularly is recommended to evacuate airborne contaminants. In sharp contrast, during the previous decades, many residences were almost sealed to save energy, e.g. to avoid heating loss. This has highly reduced air exchange with the exterior, thus increasing the concentration of pollutants. Breathing indoor gases and airborne particulate matter are therefore a major source of inhaled or ingested exposure (Koivisto et al. 2019). Recently, pollutant exposure further escalated during the coronavirus disease 2019 (COVID-19) pandemic due to people lockdown and rising teleworking (Moretti et al. 2020). Today, we spend approximately $80-90 \%$ of our time indoors, thus getting exposed to both indoor contaminants, and outdoor contaminants that enter homes and buildings via ventilation (Hussein et al. 2013). Remarkably, this exposure to mixtures of several chemicals induces adverse health effects in an additive or even supra-additive way (Lucattini et al. 2018).

The concentration of brominated flame-retardants, to which we are exposed indoors from dust particles, exceeds in general that of outdoor air (Fromme et al. 2014; Harrad et al. 2010; McGrath et al. 2018; Ni and Zeng 2013). Exposure mainly occurs through ingestion of foodstuff and inhalation of dust and airborne particles, increasing the body's burden of internal brominated flame-retardants. Health concerns have arisen following the detection of some brominated flame-retardants released into the indoor environment and subsequently taken up into human tissues (Birnbaum and Staskal 2004; USEPA 2020). Due to their persistence in the environment and their lipophilic properties, polybrominated diphenyl ethers and hexabromocyclododecane accumulate in lipidic tissues (Rivière et al. 2019; Sharkey et al. 2020a). Children are particularly exposed to brominated flame-retardants because of their hand-to-mouth behaviour and their playing on dusty grounds (Landrigan et al. 2004). Indeed, dust ingestion is the main route of exposure in children followed by indoor air inhalation and dermal contact. 


\section{High risk for children's brains}

There is growing evidence that human sensitivity to brominated flame-retardants changes at different life stages (Street et al. 2018). In particular, the toxicity of brominated flame-retardants may induce diseases a very long time after initial body contamination. In other words, an adult disease may result from foetal exposure (Grova et al. 2019). This phenomenon is rather similar to the poorlyexplored phenomenon of 'pollutant resurrection' whereby some pollutants stay trapped as bound residues in complex media, e.g. soils, then are liberated years later to induce a second wave of toxicity (Charles et al. 2021). The earlylife window of susceptibility of 1000 days between the child's conception and the age of two years old is crucial in the development of health and diseases because major changes occur during this time period in gene expression by epigenetic modifications as the infant develops (Barker and Osmond 1986). Therefore, pollutant exposure may modify epigenetic mechanisms and, in turn, implement changes that will cause adult diseases. When development is disrupted during organogenesis, there is no 'going back' and the damage becomes irreversible.

The brain is probably the most sensitive of all organs during development. For instance, exposure to polybrominated diphenyl ethers is estimated to be responsible for a cumulative loss of 162 million intelligent quotient points in American children from 2001 to 2016 (Gaylord et al. 2020). This loss is higher than that of well-known neurotoxins such as lead, mercury and pesticides. Brain development is a lifelong process starting with fertilization and continuing throughout life. In contrast to many other tissues, there are critical periods of brain sensitivity during pregnancy, the post-natal period and the first 3-6 years of life where synaptic plasticity, neurogenesis, neuronal differentiation, myelination, migration, synaptogenesis and apoptosis occur in a tightly-controlled schedule (Rice and Barone 2000). In particular, during neurogenesis, neuronal differentiation and synaptogenesis take place before birth, myelination and synaptic plasticity continue from childhood to adulthood (Lenroot and Giedd 2006). As a consequence, pregnant women, neonates, infants and young children are particularly sensitive to brominated flame-retardants, which may lead to neurodevelopmental disorders such as autism spectrum disorders and attention-deficit hyperactivity disorder (Grova et al. 2019). Pollutant-induced alteration of foetal germ cells in utero and gametes in later life may also induce transmission of the latent disease to the next generation. Thus, even though correlations between brain disorders and exposure to brominated flame-retardants are difficult to assess with absolute certainty, notably due to the presence of other pollutants, research should decipher the mechanisms of neurodevelopmental disorders induced by brominated flame-retardants.

\section{Autism spectrum disorders}

Neurodevelopmental diseases such as the autism spectrum disorder have dramatically increased recently, of 38.3\% from 1997 to 2017 (Zablotsky et al. 2019). This disorder induces a deficit in communication, struggles with social interactions, poor interests, and repetitive behaviours that appear early in life (Cattane et al. 2018; Roux and Bossu 2016). One per cent of individuals are affected by autism spectrum disorder in France (Ha et al. 2020). In the USA, the disorder for children rose from 1 out of 166 in 2004 to 1 out of 59 in 2018 (Baio et al. 2018). The disorder is probably due to a disruption in brain development, with a prevalence 3-4 times higher in boys than in girls. Research on hereditary and genetic components has disclosed more than 400 genes associated with autism spectrum disorders (Bourgeron 2015; Chaste and Leboyer 2012; Roux and Bossu 2016). Epigenomic analyses suggest that methylation-dependent transcriptional regulation is a driver in the aetiology of autism spectrum disorders (Tremblay and Jiang 2019). There is now a clear and pressing requirement to define the precise role of gene-environment interactions in autism spectrum disorders.

Exposure to chemical pollutants contributes to the aetiology of autism spectrum disorders (Grova et al. 2019; Kalkbrenner et al. 2014). Brominated flame-retardants are suspected to disrupt the thyroid axis, the oxidative stress system, immune response, and neuroinflammation (HertzPicciotto et al. 2011; Messer 2010). Hexabromocyclododecane disrupts the thyroid system in humans and other animals, and is a substance of concern for foetuses, new-borns exposed by breastfeeding, and children exposed via food and dust ingestion (Chain et al. 2021; ECHA 2019; Kim and Oh 2014). Pre-clinical early-life models confirm the toxicity of hexabromocyclododecane for the developing brain (Fernandes et al. 2021; Maurice et al. 2015). Epidemiological data suggest that in utero exposure to hexabromocyclododecane induces modifications in motor skills, attention span and metabolism (Roze et al. 2009). Nonetheless, a recent study failed to validate this hypothesis for children aged 18 months, born in mothers with a median blood hexabromocyclododecane level of $0.82 \mathrm{ng} / \mathrm{g}$ of lipids (Goodman et al. 2020).

Perinatal exposure to hexabromocyclododecane at realistic doses induced behavioural deficiencies including anxiety, locomotion and sexual activity in rats, from the age of 4 weeks until adulthood (Maurice et al. 2015). Hexabromocyclododecane exposure may induce neurodevelopmental disorders through the regulation of DNA methylation. For 
instance, 6-methyl adenine modifications have been linked to phenotypic diseases such as tumorigenesis (Xiao et al. 2018). This methylation increases with chronic stress in mice's prefrontal cortex (Yao et al. 2017). Another study suggests a potential overlap between genes that show dynamic changes in 6-methyladenine expression and genes that are involved in the onset of neuropsychiatric disorders (Armstrong et al. 2019).

Demonstrating the mechanisms underlying the developmental neurotoxicity induced by hexabromocyclododecane, especially the role of DNA methylation and other epigenetic processes, should help in understanding the pathophysiology of autism spectrum disorders and identify future therapeutic research lines. Further research is required to understand the mechanisms by which certain brominated flame-retardants could act as a factor of susceptibility in the aetiology of autism spectrum disorders. This will help in developing safer alternative products.

\section{Alternative flame retardants}

In 2017, 120,000 people died and 9 million were injured in heat-related incidents, with higher death tolls of children and the elderly (James et al. 2020). Moreover, the proportion of flammable materials in new products has increased and, in turn, has reduced the time available to escape a blaze to 3-6 $\mathrm{min}$, and the time to flashover, i.e. the time when a fire is no longer controllable, to less than $20 \mathrm{~min}$. Flame retardants therefore remain essential for building materials and furniture. Historically, organochlorines were used until evidence of their persistence, accumulation and toxicity. In the 1970s organochlorines were replaced by brominated compounds such as polybrominated diphenyl ethers, tetrabromobisphenol A and hexabromocyclododecane, which are still currently incorporated into furniture, textile, children's products, building materials and electronics. Nonetheless, from the early 2000s, the use of all organohalogenated flame retardants has declined due to mounting scientific evidence on their toxicity. Three polybrominated diphenyl ethers were banned in 2009 and 2017 by the Stockholm convention, and hexabromocyclododecane is is currently under scrutiny.

Organophosphate flame retardants have started to replace polybrominated diphenyl ethers, but recent research has disclosed toxicity at exposure levels currently reported in biota and humans (Blum et al. 2019). The incorporation of a brominated styrene-butadiene copolymer into polystyrene has been developed as an alternative to hexabromocyclododecane. This copolymer is more stable, inert and shows little to no bioavailability in environmental matrices, yet the sole published toxicological data are that of the manufacturer and the US-EPA report, which indicates a lack of acute toxicity genotoxicity, sensitization and irritation, and ecotoxicology after only 28 days of exposure (Beach et al. 2013). Hints of possible toxicity come from the fact that the brominated styrene-butadiene copolymer is synthesized from styrene and butadiene, which are known for their neurotoxic and developmental toxicity (Khalil et al. 2007).

Sustainable alternatives include glass or mineral fibres of very low organic content, which therefore do not release toxic fumes. Sandwiching a polystyrene or polyurethane layer with steel, aluminium, or mineral layers is an alternative to limit contamination and maintain insulation. The use of non-combustible interliners in aircraft seats is also very effective in reducing post-ignition fire spread and development in upholstered furniture. Last, intumescent coating systems are deposited on steel or timber surfaces to inhibit ignition and flame propagation. These coatings are made by incorporation of carbon, ammonium polyphosphate and melamine in a paint that forms a blown char when heated (Camino et al. 1989).

Acknowledgements We acknowledge the support of the Ministère de l'Enseignement supérieur et de la Recherche in France, the Luxembourg Institute of Health and the Ministry of Higher Education and Research of Luxembourg for their continued support. The work of NG, HS and CM on neurodevelopmental toxicity of HBCDD was funded by the A2F young research grant-Lorraine University and the "Ministère de l'Enseignement supérieur et de la Recherche". The work of JDT on the long-term effects of early live environmental exposure was funded by the Fonds National de la Recherche, Luxembourg, Grant numbers: C12/BM/3985792 "EpiPath", INTER/ ANR/16/11568350 "MADAM", C16/BM/11342695 "MetCOEPs", and C20/BM/14766620 "ImmunoTwin".

\section{Declarations}

Conflict of interests All the authors declare that they have no known conflict of interest.

\section{References}

Armstrong MJ, Jin Y, Allen EG, Jin P (2019) Diverse and dynamic DNA modifications in brain and diseases. Hum Mol Genet 28(R2):R241-R253. https://doi.org/10.1093/hmg/ddz179

Azuma K, Jinno H, Tanaka-Kagawa T, Sakai S (2020) Risk assessment concepts and approaches for indoor air chemicals in Japan. Int J Hyg Environ Health 225:113470. https://doi.org/10.1016/j.ijheh. 2020.113470

Baio J, Wiggins L, Christensen DL et al (2018) (2018) Prevalence of autism spectrum disorder among children aged 8 years - autism and developmental disabilities monitoring network, 11 sites, United States, 2014. MMWR Surveill Summ 67(6):1-23. https:// doi.org/10.15585/mmwr.ss6706a1

Barker DJ, Osmond C (1986) Infant mortality, childhood nutrition, and ischaemic heart disease in England and Wales. Lancet 1(8489):1077-1081

Beach MW, Beaudoin DA, Beulich I et al (2013) New class of brominated polymeric flame retardants for use in polystyrene foams. 
Cell Polym 32(4):229-236. https://doi.org/10.1177/0262489313 03200403

Birnbaum LS, Staskal DF (2004) Brominated flame retardants: cause for concern? Environ Health Perspect 112(1):9-17

Blum A, Behl M, Birnbaum LS et al (2019) Organophosphate ester flame retardants: are they a regrettable substitution for polybrominated diphenyl ethers? Environ Sci Technol Lett 6(11):638649. https://doi.org/10.1021/acs.estlett.9b00582

Bourgeron T (2015) From the genetic architecture to synaptic plasticity in autism spectrum disorder. Nat Rev Neurosci 16(9):551563. https://doi.org/10.1038/nrn3992

Camino G, Costa L, Martinasso G (1989) Intumescent fire-retardant systems. Polym Degrad Stab 23(4):359-376. https://doi.org/10. 1016/0141-3910(89)90058-X

Cattane N, Richetto J, Cattaneoa A (2018) Prenatal exposure to environmental insults and enhanced risk of developing schizophrenia and autism spectrum disorder: focus on biological pathways and epigenetic mechanisms. Neurosci Biobehav Rev. https://doi. org/10.1016/j.neubiorev.2018.07.001

EFSA Panel on Contaminants in the Food Chain (CONTAM), Schrenk D, Bignami M, Bodin L, Chipman JK, del Mazo J, Grasl-Kraupp B, Hogstrand C, Hoogenboom L, Leblanc JC, Nebbia CS, Nielsen E, Ntzani E, Petersen A, Sand S, Schwerdtle T, Wallace $\mathrm{H}$, Benford D, F€urst P, Rose M, Ioannidou S, Nikoli M, Bordajandi LR, Vleminckx C (2021) Update of the risk assessment of hexabromocyclododecanes (HBCDDs) in food. EFSA Journal 19(3):e06421. https://doi.org/10.2903/j. efsa.2021.6421

Chaste P, Leboyer M (2012) Autism risk factors: genes, environment, and gene-environment interactions. Dialogues Clin Neurosci 14(3):281-292

Charles M, Pierre S, Olivier E et al (2021) Pesticide resurrection. Environ Chem Lett. https://doi.org/10.1007/s10311-021-01347-z

ECHA (2019) Member state committee support document for identification of hexabromocyclododecane and all major diastereoisomers as a substance of very high concern, 2009. https://echa. europa.eu/documents/10162/47d061d9-e336-4139-883b-f0033 1278 cda (consulté le 28/03/2019).

Fernandes SB, Grova N, Roth S et al (2021) N6-Methyladenine in Eukaryotic DNA: tissue distribution, early embryo development, and neuronal toxicity. Frontiers in Genetics. https://doi. org/10.3389/fgene.2021.657171

Frederiksen M, Vorkamp K, Thomsen M, Knudsen LE (2009) Human internal and external exposure to PBDEs - a review of levels and sources. Int J Hyg Environ Health 212(2):109-134. https://doi.org/10.1016/j.ijheh.2008.04.005

Fromme H, Hilger B, Kopp E, Miserok M, Völkel W (2014) Polybrominated diphenyl ethers (PBDEs), hexabromocyclododecane (HBCD) and "novel" brominated flame retardants in house dust in Germany. Environ Int 64:61-68. https://doi.org/10.1016/j. envint.2013.11.017

Gaylord A, Osborne G, Ghassabian A, Malits J, Attina T, Trasande L (2020) Trends in neurodevelopmental disability burden due to early life chemical exposure in the USA from 2001 to 2016: a population-based disease burden and cost analysis. Mol Cell Endocrinol 502:110666. https://doi.org/10.1016/j.mce.2019. 110666

Goodman M, Li J, Flanders WD et al (2020) Epidemiology of PCBs and neurodevelopment: Systematic assessment of multiplicity and completeness of reporting. Global Epidemiology 2:100040. https://doi.org/10.1016/j.gloepi.2020.100040

Gray WA, Billock VA (2017) Developmental neurotoxicity and autism: a potential link between indoor neuroactive pollutants and the curious birth order risk factor. Int J Dev Neurosci 62(1):32-36. https://doi.org/10.1016/j.ijdevneu.2017.07.004
Grova N, Schroeder H, Olivier JL, Turner JD (2019) Epigenetic and neurological impairments associated with early life exposure to persistent organic pollutants. Int J Genomics 2019:2085496. https://doi.org/10.1155/2019/2085496

Ha C, Chin F, C. CC (2020) roubles du spectre de l'autisme en France. Estimation de la prévalence à partir du recours aux soins dans le Système national des données de santé (SNDS), France, 20102017. Santé Publique France ETudes et enqu^tes: 37

Harrad S, de Wit CA, Abdallah MA et al (2010) Indoor contamination with hexabromocyclododecanes, polybrominated diphenyl ethers, and perfluoroalkyl compounds: an important exposure pathway for people? Environ Sci Technol 44(9):3221-3231. https://doi. org/10.1021/es903476t

Hertz-Picciotto I, Bergman A, Fangstrom B et al (2011) Polybrominated diphenyl ethers in relation to autism and developmental delay: a case-control study. Environ Health 10(1):1. https://doi. org/10.1186/1476-069x-10-1

Hussein T, Löndahl J, Paasonen P et al (2013) Modeling regional deposited dose of submicron aerosol particles. Sci Total Environ 458-460:140-149. https://doi.org/10.1016/j.scitotenv.2013.04.022

James SL, Lucchesi LR, Bisignano C et al (2020) Epidemiology of injuries from fire, heat and hot substances: global, regional and national morbidity and mortality estimates from the Global Burden of Disease 2017 study. Inj Prev 26(Suppl 2):i36. https://doi. org/10.1136/injuryprev-2019-043299

Kalkbrenner AE, Schmidt RJ, Penlesky AC (2014) Environmental chemical exposures and autism spectrum disorders: a review of the epidemiological evidence. Curr Probl Pediatr Adolesc Health Care 44(10):277-318. https://doi.org/10.1016/j.cppeds.2014.06. 001

Khalil M, Abudiab M, Ahmed AE (2007) Clinical evaluation of 1,3-butadiene neurotoxicity in humans. Toxicol Ind Health 23(3):141-146. https://doi.org/10.1177/0748233707078773

Kim UJ, Oh JE (2014) Tetrabromobisphenol a and hexabromocyclododecane flame retardants in infant-mother paired serum samples, and their relationships with thyroid hormones and environmental factors. Environ Pollut 184:193-200. https://doi.org/10.1016/j. envpol.2013.08.034

Koivisto AJ, Kling KI, Hanninen O et al (2019) Source specific exposure and risk assessment for indoor aerosols. Sci Total Environ 668:13-24. https://doi.org/10.1016/j.scitotenv.2019.02.398

Landrigan PJ, Kimmel CA, Correa A, Eskenazi B (2004) Children's health and the environment: public health issues and challenges for risk assessment. Environ Health Perspect 112(2):257-265. https://doi.org/10.1289/ehp.6115

Lenroot RK, Giedd J (2006) Brain development in children and adolescents: insights from anatomical magnetic resonance imaging, vol 30,

Lucattini L, Poma G, Covaci A, de Boer J, Lamoree MH, Leonards PEG (2018) A review of semi-volatile organic compounds (SVOCs) in the indoor environment: occurrence in consumer products, indoor air and dust. Chemosphere 201:466-482. https:// doi.org/10.1016/j.chemosphere.2018.02.161

Malkoske T, Tang Y, Xu W, Yu S, Wang H (2016) A review of the environmental distribution, fate, and control of tetrabromobisphenol a released from sources. Sci Total Environ 569-570:1608-1617. https://doi.org/10.1016/j.scitotenv.2016.06.062

Malliari E, Kalantzi OI (2017) Children's exposure to brominated flame retardants in indoor environments - a review. Environ Int 108:146-169. https://doi.org/10.1016/j.envint.2017.08.011

Maurice N, Olry JC, Cariou R et al (2015) Short-term effects of a perinatal exposure to the HBCDD alpha-isomer in rats: assessment of early motor and sensory development, spontaneous locomotor activity and anxiety in pups. Neurotoxicol Teratol 52(Pt B):170180. https://doi.org/10.1016/j.ntt.2015.08.005 
McGrath TJ, Morrison PD, Ball AS, Clarke BO (2018) Concentrations of legacy and novel brominated flame retardants in indoor dust in Melbourne, Australia: an assessment of human exposure. Environ Int 113:191-201. https://doi.org/10.1016/j.envint.2018.01.026

Messer A (2010) Mini-review: polybrominated diphenyl ether (PBDE) flame retardants as potential autism risk factors. Physiol Behav 100(3):245-249. https://doi.org/10.1016/j.physbeh.2010.01.011

Moretti A, Menna F, Aulicino M, Paoletta M, Liguori S, Iolascon G (2020) Characterization of home working population during COVID-19 emergency: a cross-sectional analysis. Int J Environ Res Public Health 17(17):6284

Ni H-G, Zeng H (2013) HBCD and TBBPA in particulate phase of indoor air in Shenzhen, China. Sci Total Environ 458-460:15-19. https://doi.org/10.1016/j.scitotenv.2013.04.003

Rice D, Barone S (2000) Critical periods of vulnerability for the developing nervous system: evidence from humans and animal models. Environ Health Perspect 108:511-533. https://doi.org/10.2307/ 3454543

Rivière G, Jean J, Gorecki S et al (2019) Dietary exposure to perfluoroalkyl acids, brominated flame retardants and health risk assessment in the French infant total diet study. Food Chem Toxicol 131:110561. https://doi.org/10.1016/j.fct.2019.06.008

Roux S, Bossu JL (2016) The cerebellum: from motor diseases to autism. Rev Neuropsychol 8(3):182-191

Roze E, Meijer L, Bakker A, Van Braeckel KNJA, Sauer PJJ, Bos AF (2009) Prenatal exposure to organohalogens, including brominated flame retardants, influences motor, cognitive, and behavioral performance at school age. Environ Health Perspect 117(12):1953-1958. https://doi.org/10.1289/ehp.0901015

Ryan JJ, Rawn DF (2014) The brominated flame retardants, PBDEs and HBCD, in Canadian human milk samples collected from 1992 to 2005; concentrations and trends. Environ Int 70:1-8. https://doi. org/10.1016/j.envint.2014.04.020
Sharkey M, Harrad S, Abou-Elwafa Abdallah M, Drage DS, Berresheim H (2020a) Phasing-out of legacy brominated flame retardants: The UNEP Stockholm convention and other legislative action worldwide. Environ Int 144:106041. https://doi.org/10. 1016/j.envint.2020.106041

Street ME, Angelini S, Bernasconi S et al (2018) Current knowledge on endocrine disrupting chemicals (EDCs) from animal biology to humans, from pregnancy to adulthood: highlights from a national Italian meeting. Int J Mol Sci 19(6):1647. https://doi.org/10.3390/ ijms 19061647

Tremblay MW, Jiang Y-H (2019) DNA Methylation and susceptibility to autism spectrum disorder. Annu Rev Med 70:151-166. https:// doi.org/10.1146/annurev-med-120417-091431

USEPA (2020) Risk evaluation for cyclic aliphatic bromide cluster (HBCD). USEPA, p 723

Xiao C-L, Zhu S, He M et al (2018) $\mathrm{N}<$ sup $>6</$ sup $>$-Methyladenine DNA modification in the human genome. Mol Cell 71(2):306-318. e7. https://doi.org/10.1016/j.molcel.2018.06.015

Yao B, Cheng Y, Wang Z et al (2017) DNA N6-methyladenine is dynamically regulated in the mouse brain following environmental stress. Nat Commun 8(1):1122. https://doi.org/10.1038/ s41467-017-01195-y

Zablotsky B, Black LI, Maenner MJ et al (2019) Prevalence and trends of developmental disabilities among children in the United States: 2009-2017. Pediatrics 144(4):e20190811. https://doi.org/10.1542/ peds.2019-0811

Publisher's Note Springer Nature remains neutral with regard to jurisdictional claims in published maps and institutional affiliations. 